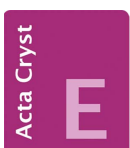

CRYSTALLOGRAPHIC COMMUNICATIONS

ISSN 2056-9890

Received 17 May 2017

Accepted 3 June 2017

Edited by S. Parkin, University of Kentucky, USA

Keywords: crystal structure; order/disorder transition; hydrogen carbonate.

CCDC references: 1554022; 1554021

Supporting information: this article has supporting information at journals.iucr.org/e

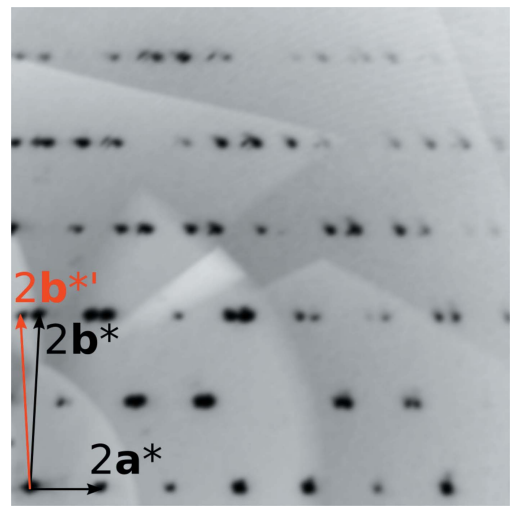

OPEN $\odot$ ACCESS

\section{The phase transition of rubidium hydrogen carbonate, $\mathrm{RbHCO}_{3}$}

\author{
Carla Larvor $^{\mathrm{a}}$ and Berthold Stöger ${ }^{\mathrm{b} *}$
}

a'Département Mesures Physique, Institut Universitaire Téchnologique de Bordeaux, 15 Rue de Naudet, 33175 Gradignan, France, and ${ }^{\mathbf{b}} \mathrm{X}$-Ray Centre, TU Wien, Getreidemarkt 9, A-1060 Vienna, Austria. *Correspondence e-mail: bstoeger@mail.tuwien.ac.at

Rubidium hydrogen carbonate, $\mathrm{RbHCO}_{3}$, features an order/disorder phase transition at $T_{\mathrm{C}}=245 \mathrm{~K}$ from the high-temperature (HT) disordered $C 2 / m$ modification to the low-temperature (LT) $C \overline{1}$ modification. The crystal structures are characterized by $\left[\mathrm{HCO}_{3}\right]_{2}{ }^{2-}$ pairs of hydrogen carbonate groups connected by strong hydrogen bonding. The $\left[\mathrm{HCO}_{3}\right]_{2}^{2-}$ pairs are connected by $\mathrm{Rb}^{+}$cations into a three-dimensional network. In HT- $\mathrm{RbHCO}_{3}$, the hydrogen atom is disordered. In LT- $\mathrm{RbHCO}_{3}$, ordering of the hydrogen atom leads to a translationengleiche symmetry reduction of index 2 . The lost reflections and rotations are retained as twin operations.

\section{Chemical context}

The crystal chemistry of partially protonated oxoanions of main group elements [e.g. hydrogen carbonates, (di)hydrogen phosphates, hydrogen sulfates etc] is characterized by the formation of strong hydrogen bonds. Topologically, the hydrogen-bonding network may lead to isolated units (e.g. pairs in $\mathrm{KHCO}_{3}$; Thomas et al., 1974), infinite chains (e.g. $\mathrm{NaHCO}_{3}$; Sass \& Scheuerman, 1962) or two-dimensional networks (e.g. $\mathrm{CsH}_{2} \mathrm{PO}_{4}$; Uesu \& Kobayashi, 1976). Compounds with such extended hydrogen-bonded network structures may be useful as proton conductors (Kim et al., 2015).

In many cases, at higher temperatures, the hydrogen atoms are dynamically disordered between the connected oxoanions. On cooling, the disorder is 'frozen', resulting in a reduction of symmetry (order/disorder phase transition). Such phase transitions are of technological importance, for example in the $\mathrm{KH}_{2} \mathrm{PO}_{4}$ (KDP) family of compounds and therefore have been studied extensively. At high temperatures, these compounds exist in a paraelectric tetragonal phase. On cooling below $T_{\mathrm{C}}$, they order into orthorhombic ferroelectrics. This kind of phase transition is likewise of theoretical interest, because it allows the study of proton quantum dynamics (Fillaux et al., 2008).

From a crystallographic point of view, these phase transitions offer the potential to study group/subgroup relationships (Müller, 2013). Moreover, in the case of a reduction of point symmetry, the lost symmetry is typically retained as a twin operation, leading to interesting as well as challenging problems.

A well known example of a hydrogen-bonding order/ disorder transition is potassium hydrogen carbonate, $\mathrm{KHCO}_{3}$ (Kashida \& Yamamoto, 1990). Above $T_{\mathrm{C}}=318 \mathrm{~K}$, it crystallizes in a monoclinic $C 2 / \mathrm{m}$ phase featuring disorder of the 
Table 1

Hydrogen-bond geometry $\left(\AA,^{\circ}\right)$ for HT-RbHCO3.

\begin{tabular}{lllll}
\hline$D-\mathrm{H} \cdots A$ & $D-\mathrm{H}$ & $\mathrm{H} \cdots A$ & $D \cdots A$ & $D-\mathrm{H} \cdots A$ \\
\hline $\mathrm{O} 2-\mathrm{H} \cdots \mathrm{O} 2^{\mathrm{i}}$ & $0.85(4)$ & $1.75(4)$ & $2.571(3)$ & $162(6)$ \\
\hline
\end{tabular}

Symmetry code: (i) $-x+1, y,-z+1$.

Table 2

Hydrogen-bond geometry $\left(\AA{ }^{\circ}\right)$ for LT-RbHCO3.

\begin{tabular}{lllll}
\hline$D-\mathrm{H} \cdots A$ & $D-\mathrm{H}$ & $\mathrm{H} \cdots A$ & $D \cdots A$ & $D-\mathrm{H} \cdots A$ \\
\hline $\mathrm{O} 2-\mathrm{H} \cdots \mathrm{O}^{\mathrm{i}}$ & $0.85(3)$ & $1.75(3)$ & $2.582(3)$ & $165(4)$ \\
\hline
\end{tabular}

Symmetry code: (i) $-x+1,-y+1,-z+1$.

hydrogen atom (Fillaux et al., 2008). On cooling, it transforms into an ordered $P 2_{1} / a$ phase (Thomas et al., 1974). Rubidium hydrogen carbonate $\mathrm{RbHCO}_{3}$ shows an analogous phase transition at $T_{\mathrm{C}}=245 \mathrm{~K}$, which has been thoroughly studied by NMR spectroscopy (Odin, 2004). The published structural data, on the other hand, leave much to be desired. A structure model of the high-temperature (HT) modification in the $C 2$ space group has been provided by Kim (1969). The structure was later redetermined by Cirpus (1997), establishing the correct space group $\mathrm{C} 2 / \mathrm{m}$ and isotypism with $\mathrm{KHCO}_{3}$. The lattice metrics of the low-temperature (LT) modification were identified as triclinic by Müller \& Roth (2005). Although a model was refined by these authors, structural data were not deposited. To fill this gap, in this communication we report detailed structural data of the LT modification of $\mathrm{RbHCO}_{3}$ which were derived from a twinned crystal. We also redetermined the structure of the HT modification. The phase transition is discussed in detail and contrasted to the structural changes observed in $\mathrm{KHCO}_{3}$.

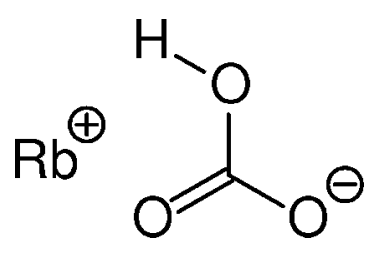

\section{Structural commentary}

\subsection{General}

The structure model of $\mathrm{HT}-\mathrm{RbHCO}_{3}(\mathrm{C} 2 / \mathrm{m})$ is in good agreement with that of Cirpus (1997). The crystal structures of

$\left[\mathrm{HCO}_{3}\right]_{2}{ }^{2-}$ pair in $\mathrm{LT}-\mathrm{RbHCO}_{3}$ connected by strong hydrogen bonding. C and $\mathrm{O}$ atoms are represented by grey and red ellipsoids drawn at the $75 \%$ probability levels and $\mathrm{H}$ atoms by white spheres of arbitrary radius. Hydrogen bonding is indicated by dashed lines.

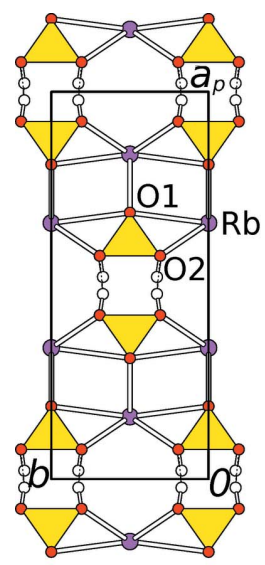

(a)

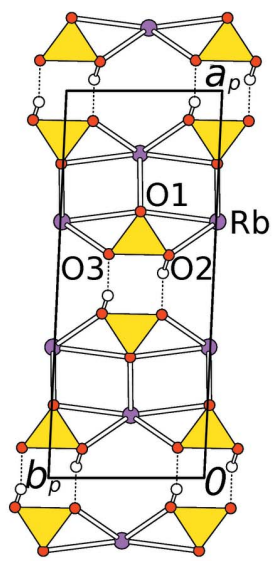

(b)

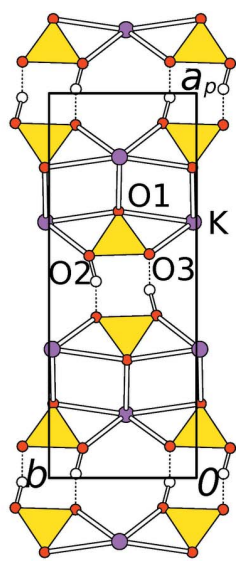

(c)
Figure 2

The crystal structures of (a) HT- $\mathrm{RbHCO}_{3},(b) \mathrm{LT}^{-\mathrm{RbHCO}_{3}}$ and (c) LT$\mathrm{KHCO}_{3}$ viewed down [001]. Rb/K atoms are represented by purple spheres, $\mathrm{O}$ atoms by red spheres, $\mathrm{H}$ atoms by colourless spheres and $\mathrm{CO}_{3}{ }^{2-}$ groups by yellow triangles.

$\mathrm{HT}_{-\mathrm{RbHCO}_{3}}(\mathrm{C} 2 / m)$ and LT-RbHCO3 $(\mathrm{C} \overline{1})$ are closely related. The central building blocks are pairs of $\mathrm{HCO}_{3}{ }^{-}$anion groups, which are connected by strong hydrogen bonds (Fig. 1, Tables 1 and 2). The prime cause for the order/disorder phase transition is the dynamic behaviour of the protons in these pairs. In HT- $\mathrm{RbHCO}_{3}$, they are dynamically disordered, resulting in a short [C-O1: 1.237 (4) $\AA$ ] and two symmetryequivalent intermediate $[2 \times \mathrm{C}-\mathrm{O} 2: 1.307$ (3) $\AA$ ] $\mathrm{C}-\mathrm{O}$ bonds. The $\left[\mathrm{HCO}_{3}\right]_{2}{ }^{2-}$ pair accordingly possesses $2 / m$ point group symmetry. On cooling, the protons cannot overcome the tunneling barrier and are attached to distinct $\mathrm{O}$ atoms. In

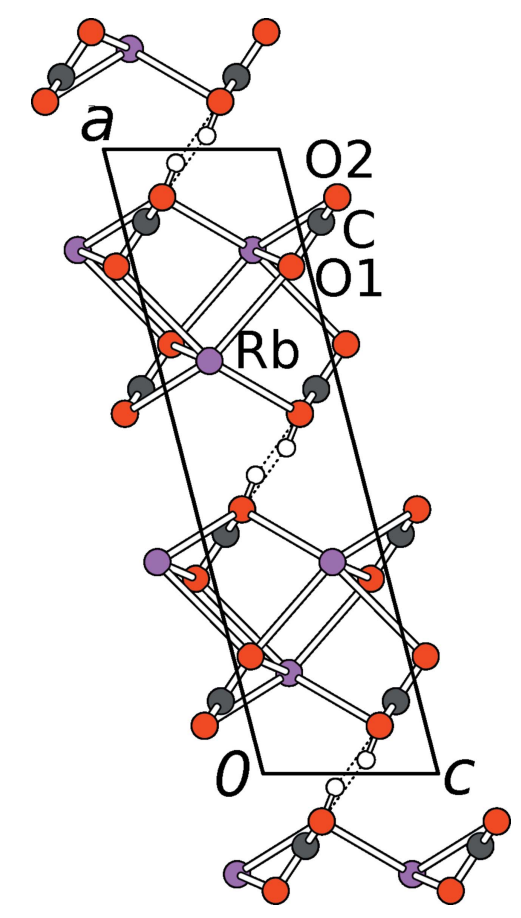

Figure 3

The crystal structure of $\mathrm{HT}-\mathrm{RbHCO}_{3}$ viewed down [010]. Atoms as in Fig. 2, $\mathrm{C}$ atoms are grey. 


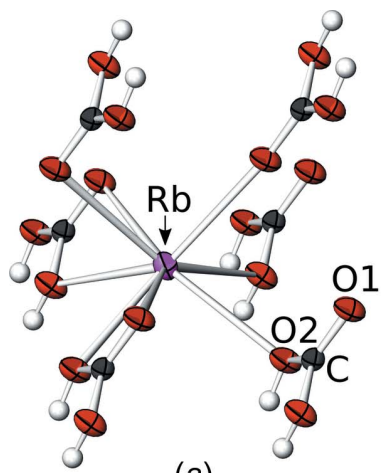

(a)

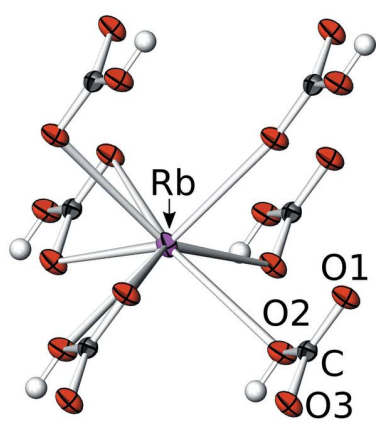

(b)
Figure 4

Coordination environment of the $\mathrm{Rb}^{+}$cations in (a) HT- $\mathrm{RbHCO}_{3}$ and $(b)$ LT- $\mathrm{RbHCO}_{3}$. Atoms as in Fig. $1, \mathrm{Rb}^{+}$cation are purple.

consequence, the point group symmetry of the $\left[\mathrm{HCO}_{3}\right]_{2}{ }^{2-}$ pair is reduced to $\overline{1}$. There are two short [C-O1: 1.241 (4) $\AA, \mathrm{C}-$ O3: 1.270 (4) $\AA$ ] and one longer [C-O2: 1.349 (4) $\AA]$ bond, as is characteristic for partially hydrogenated oxoanions. In both cases, the $\mathrm{HCO}_{3}{ }^{-}$group is flat [distance of the $\mathrm{C}$ atom to the plane defined by the three O atoms: 0.000 (4) $\AA$ (HT) and 0.007 (3) $\AA$ (LT)], in accordance with literature data (Zemann, 1981).

The $\left[\mathrm{HCO}_{3}\right]_{2}^{2-}$ pairs are connected by the $\mathrm{Rb}^{+}$cations into a three-dimensional network (Figs. 2 and 3). The $\mathrm{Rb}^{+}$cations are located on the reflection plane of the $C 2 / m$ group (HT$\mathrm{RbHCO}_{3}$ ) or on general positions $\left(\mathrm{LT}-\mathrm{RbHCO}_{3}\right)$. They are connected to six carbonate groups, two of which coordinate in a bidentate manner, the four others via one $\mathrm{O}$ atom (Fig. 4). Thus, in total, the $\mathrm{Rb}^{+}$cations are coordinated by eight $\mathrm{O}$ atoms with bond lengths in the ranges 2.869 (3)-3.0662 (12) $\AA$ ( $\left.\mathrm{HT}-\mathrm{RbHCO}_{3}\right)$ and $2.865(3)-3.101(2) \AA\left(\mathrm{LT}-\mathrm{RbHCO}_{3}\right)$.

\subsection{Symmetry reduction and relationship to $\mathrm{KHCO}_{3}$}

Whereas the $\mathrm{HT}-\mathrm{KHCO}_{3}$ and $\mathrm{HT}-\mathrm{RbHCO}_{3}$ phases are isotypic, the corresponding LT phases are not. To understand the different behaviour on cooling, it is useful to consider the structures as being made up of layers of $\left[\mathrm{HCO}_{3}\right]_{2}^{2-}$ pairs parallel to (100). In the HT phases, these layers possess the $p 12 / m 1$ layer group symmetry. On cooling, owing to the ordering of the protons, the $m_{[010]}$ operation is lost. All $\left[\mathrm{HCO}_{3}\right]_{2}{ }^{2-}$ pairs are rotated in the same direction about [001], resulting in layers with $p \overline{1}$ symmetry.

Thus, the lower symmetry layers may appear in one out of two orientations with respect to the [010] direction. In the LT$\mathrm{RbHCO}_{3}$ phase, all layers feature the same orientation. Adjacent layers are related by translation symmetry (as in the $\mathrm{C} 2 / \mathrm{m}$ HT phase) and therefore the translation lattice is retained. The symmetry loss concerns only the point symmetry. Since one out of two symmetry operations is retained (viz. the translations and inversions), the symmetry reduction is of the $t 2 \mathrm{kind}$, where $t$ stands for translationengleiche and 2 for the index of $\overline{1}$ in 2/m (Müller, 2013).

In the LT- $\mathrm{KHCO}_{3}$ phase, on the other hand, layers feature alternating orientation with respect to [010]. The layers are split in two sets of translationally equivalent layers. The translation lattice is therefore reduced by an index of two, which here corresponds to a change of the Bravais lattice $(m C$ to $m P$ ) while retaining the volume of the cell in the (more convenient but non-standard) centred setting. In return, adjacent layers are related by an $a$ glide reflection. Thus, the point symmetry $2 / m$ is retained. The symmetry reduction is therefore of the $k 2$ kind, where $k$ stands for klassengleiche (Müller, 2013).

The structural relationships of the HT and LT phases of $\mathrm{RbHCO}_{3}$ and $\mathrm{KHCO}_{3}$ are represented in a Bärnighausen family tree in Fig. 5. The atomic labelling and coordinates of the $\mathrm{KHCO}_{3}$ modifications were adapted from the original literature (Fillaux et al., 2008; Thomas et al., 1974) to be comparable to the data presented here. Note that the fractional coordinates of all four phases depicted in Fig. 5 are remarkably similar.

The atoms on the reflection planes in the HT phases are located on general positions in the LT phases. The $\mathrm{O} 2$ atom, which is located on a general position in the HT phase, is split into two positions in the LT phase. In contrast, the position of the $\mathrm{H}$ atom, which is also located on a general position in the HT modification, is not split. Instead, its occupancy is raised from 0.5 to 1 .

\begin{tabular}{|c|c|c|c|c|c|}
\hline & $\begin{array}{c}\mathrm{K}: 4 i \\
m\end{array}$ & $\begin{array}{c}\mathrm{O} 1: 4 i \\
m\end{array}$ & $\begin{array}{c}\mathrm{O} 2: 8 j \\
1\end{array}$ & $\begin{array}{c}\text { C: } 4 i \\
m\end{array}$ & $\begin{array}{c}\mathrm{H}: 8 j \\
1\end{array}$ \\
\hline & 0.665 & 0.693 & 0.578 & 0.620 & 0.518 \\
\hline & 0 & $1 / 2$ & 0.302 & $1 / 2$ & 0.313 \\
\hline & 0.296 & 1.095 & 0.736 & 0.856 & 0.561 \\
\hline & $01 \cdot 4 e$ & 2. & 03.40 & $\frac{\downarrow}{C \cdot 4 e}$ & $\downarrow$ \\
\hline 1 & 1 & 1 & 1 & 1 & 1 \\
\hline 0.665 & 0.693 & 0.578 & 0.582 & 0.620 & 0.511 \\
\hline-0.022 & 0.471 & 0.272 & 0.680 & 0.485 & 0.318 \\
\hline 0.295 & 1.095 & 0.726 & 0.726 & 0.856 & 0.535 \\
\hline
\end{tabular}

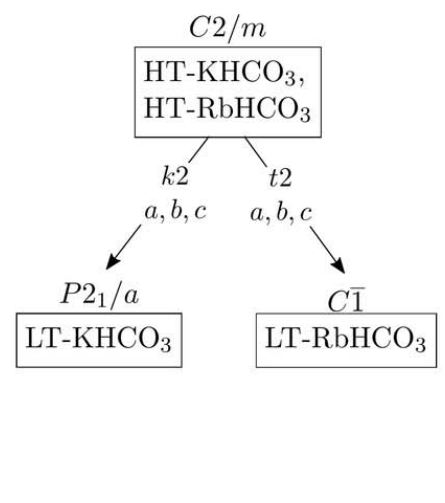

\begin{tabular}{|c|c|c|c|c|c|}
\hline $\begin{array}{c}\text { Rb: } 4 i \\
m\end{array}$ & O1: $4 i$ & O2: $8 j$ & $\mathrm{C}: 4 i$ & $\mathrm{H}: 8 j$ \\
$m$ & 1 & $m$ & 1 \\
\cline { 1 - 5 } 0.661 & 0.688 & 0.577 & 0.616 & 0.522 \\
0 & $1 / 2$ & 0.308 & $1 / 2$ & 0.328 \\
0.295 & 1.100 & 0.735 & 0.864 & 0.608 \\
\hline
\end{tabular}

Figure 5

Bärnighausen family tree (Bärnighausen, 1980) representing the symmetry reduction from the HT- $\mathrm{KHCO}_{3}$ and $\mathrm{RbHCO}_{3}$ modifications to their LT modifications. Coordinates of the $\mathrm{KHCO}_{3}$ modifications were adapted from Fillaux et al. (2008) and Thomas et al. (1974). 


\subsection{Twinning}

Phase transitions are one of the classical causes of twinning (Hahn \& Klapper, 2006; Stöger et al., 2016). If the point symmetry of the structure is reduced, the lost operations may be retained as twin operations. Indeed, the crystals of $\mathrm{RbHCO}_{3}$ were all systematically twinned below $T_{\mathrm{C}}$. The crystal under investigation was made up of two domains related by $m_{[010]}$ and equivalently $2_{[010]}$, which corresponds precisely to the second coset in the coset decomposition of $\overline{1}$ in $2 / \mathrm{m}$. The twin volume ratio was determined by the TWINABS software as 51.3:48.7, which compares well to the volume ratio obtained from the (abandoned, see Section 3.3) refinement against HKLF 5 style data [52.0:48.0 (4)].

Since the transformation into the triclinic $C \overline{1}$ LT phase results in a substantial increase of the $\gamma$ angle to $\gamma=$ $92.748(9)^{\circ}$, the diffraction spots at higher $k$ indices are clearly separated (Fig. 6). Such a twin cannot be treated as a twin by pseudo-merohedry. The $\alpha$ angle, on the other hand, deviates only slightly from the monoclinic metrics $\left[\alpha=89.343(4)^{\circ}\right]$. The lattice of the layers therefore is pseudo-rectangular, which is consistent with the crystallo-chemical considerations above.

In $\mathrm{KHCO}_{3}$, the $\mathrm{HT}$ and LT phase feature the same point symmetry $2 / \mathrm{m}$. Stacking faults therefore do not result in twinning but in antiphase domains (Wondratschek \& Jeitschko, 1976). These kinds of domains are significantly more difficult to quantify using X-ray diffraction.

\section{Experimental}

\subsection{Synthesis and crystallization}

Large crystals of $\mathrm{RbHCO}_{3}$ were grown by dissolving commercial ' $\mathrm{Rb}_{2} \mathrm{CO}_{3}$ ' (actually the sesquihydrate according to powder X-ray diffraction) in a small quantity of water followed by evaporation of the solution overnight at $c a 295 \mathrm{~K}$.

\subsection{Data collection}

Crystals were cut to sizes suitable for single crystal diffraction with a razor blade. Abrupt cooling of the crystals to below the phase-transition temperature by immersion into a cooled $\mathrm{N}_{2}$ stream led to fourfold splitting of reflections as described by Müller \& Roth (2005). Data reduction was successful using four orientation matrices and a reasonable structure model could be obtained. Nevertheless, the quality of the refinement was deemed not optimal (notably, the hydrogen atoms could not be located). From structural reasoning, only two domains are expected (see Section 2.2). The higher number of domains was therefore attributed to a cracking of the crystal under thermal stress. Therefore, a data collection was first performed above $T_{\mathrm{C}}$ at $270 \mathrm{~K}$. Then, the crystal was slowly $\left(2 \mathrm{~K} \mathrm{~h}^{-1}\right)$ cooled to $200 \mathrm{~K}$ and a full sphere of reciprocal space was collected with fine slicing. The first scan was discarded because it contained distinct reflections from the HT phase as well as two LT domains. The data set obtained from the remaining scans featured only the two expected LT twin domains.

\subsection{Data processing}

Data of the HT modification was subjected to routine processing using SAINT and SADABS (Bruker, 2016). For the LT phase, reflections of both domains were separated and reduced to intensity data using overlap information. An absorption correction was applied using the TWINABS (Bruker, 2016) software. This software outputs 'detwinned' conventional data (HKLF 4 style), usually used for structure solution and data with overlap information (HKLF 5 style). Surprisingly, the detwinned data set resulted in significantly better refinements. Not only were the residuals lower by two percentage points, additionally only in the detwinned data could the hydrogen atoms be located and refined. Therefore the discussion is based on the refinement using the detwinned data set.

\subsection{Structure solution and refinement}

An initial model of the HT modification was adapted from the data of Cirpus (1997). The structure of the LT modification was solved using the dual-space approach implemented in SHELXT (Sheldrick, 2015). Atomic coordinates and labelling were adapted to be analogous to those of the HT modification. The non-standard $C \overline{1}$ setting of the $P \overline{1}$ space group was chosen to facilitate comparison with the HT modification [lattice basis transformation from $P \overline{1}$ to $C \overline{1}:\left(\mathbf{a}_{C}, \mathbf{b}_{C}, \mathbf{c}_{C}\right)=\left(\mathbf{b}_{P}+2 \mathbf{c}_{P},-\mathbf{b}_{P}\right.$, $\left.\mathbf{a}_{P}\right)$ ]. The structure models were refined against $F^{2}$ with JANA2006 (Petříček et al., 2014). The hydrogen atoms were located in difference Fourier maps and the $\mathrm{O}-\mathrm{H}$ distances restrained to 0.850 (1) $\AA$. Crystal data, data collection and structure refinement details are summarized in Table 3.

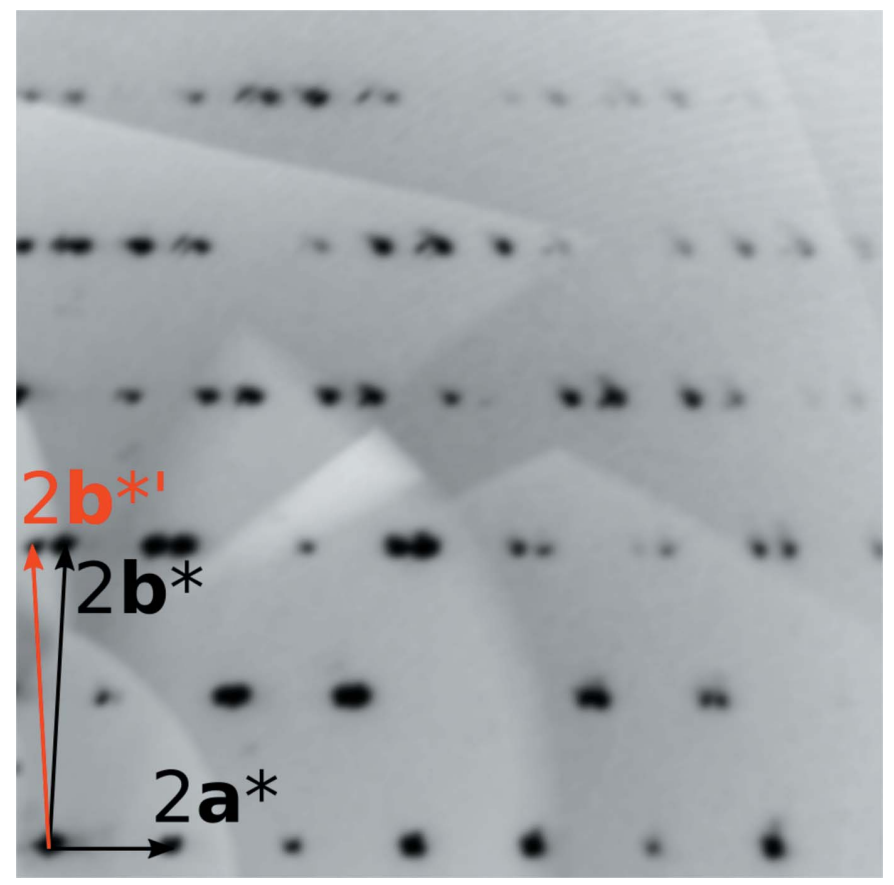

Figure 6

Part of the $h k 2$ plane in reciprocal space of $\mathrm{LT}-\mathrm{RbHCO}_{3}$ reconstructed from CCD data. The reciprocal basis vectors of the two twin domains are indicated. 
Table 3

Experimental details.

$\mathrm{HT}-\mathrm{RbHCO}_{3}$

$\mathrm{RbHCO}_{3}$
146.5
Monoclinic, $C 2 / m$
270
$14.807(3), 5.8216(12), 4.0217(9)$
$90,104.321(5), 90$
$335.91(12)$
4
$\mathrm{Mo} \mathrm{K \alpha}$
14.54
$0.43 \times 0.18 \times 0.09$

Bruker Kappa APEXII CCD

Multi-scan (SADABS; Bruker, 2016)

$0.05,0.27$

$3067,672,544$

0.051

0.766

$0.029,0.066,1.26$

672

32

1

$\mathrm{H}$ atoms treated by a mixture of independent and constrained refinement $0.86,-0.96$
$\mathrm{LT}-\mathrm{RbHCO}_{3}$

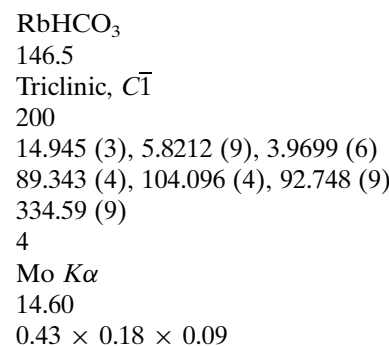

Bruker Kappa APEXII CCD

Multi-scan (TWINABS; Bruker, 2016)

$0.05,0.27$

$8005,1215,1029$

0.059

0.760

$0.038,0.075,1.50$

1215

50

1

$\mathrm{H}$ atoms treated by a mixture of independent and constrained refinement

$1.88,-1.81$

$\Delta \rho_{\max }, \Delta \rho_{\min }\left(\mathrm{e} \AA^{-3}\right)$

Computer programs: APEX3 and SAINT-Plus (Bruker, 2016), SHELXT (Sheldrick, 2015), JANA2006 (Petř́ícek et al., 2014), ATOMS (Dowty, 2006) and publCIF (Westrip, 2010).

\section{References}

Bärnighausen, H. (1980). MATCH Commun. Math. Comput. Chem. 9, 139-175.

Bruker (2016). APEX3, SAINT, SADABS and TWINABS. Bruker Analytical X-ray Instruments Inc., Madison, Wisconsin, USA.

Cirpus, V. (1997). Beiträge zur Kristallchemie der Alkalimetallcarbonate und -hydrogencarbonate. Dissertation, Universität Köln, Germany.

Dowty, E. (2006). ATOMS. Shape Software, 521 Hidden Valley Road, Kingsport, TN 37663, USA.

Fillaux, F., Cousson, A. \& Gutmann, M. J. (2008). J. Phys. Condens. Matter, 20, 015225-, 1-01522510.

Hahn, Th. \& Klapper, H. (2006). Twinning of crystals. In: Physical properties of crystals, Volume $D$ of International Tables For Crystallography, ch. 3.3. IUCr, Chester.

Kashida, S. \& Yamamoto, K. (1990). J. Solid State Chem. 86, 180-187. Kim, M. I. (1969). J. Korean Chem. Soc. 13, 131-136.
Kim, G., Griffin, J. M., Blanc, F., Haile, S. M. \& Grey, C. P. (2015). J. Am. Chem. Soc. 137, 3867-3876.

Müller, U. (2013). Symmetry Relationships between Crystal Structures. Oxford University Press, Oxford.

Müller, R. \& Roth, G. (2005). J. Appl. Cryst. 38, 280-290.

Odin, C. (2004). Magn. Reson. Chem. 42, 381-388.

Petříček, V., Dušek, M. \& Palatinus, L. (2014). Z. Kristallogr. 229, 345-352.

Sass, R. L. \& Scheuerman, R. F. (1962). Acta Cryst. 15, 77-81.

Sheldrick, G. M. (2015). Acta Cryst. A71, 3-8.

Stöger, B., Weil, M., Murugesan, S. \& Kirchner, K. (2016). Z. Kristallogr. 231, 601-622.

Thomas, J. O., Tellgren, R. \& Olovsson, I. (1974). Acta Cryst. B30, $1155-1166$.

Uesu, Y. \& Kobayashi, J. (1976). Phys. Stat. Sol. (A), 34, 475-481.

Westrip, S. P. (2010). J. Appl. Cryst. 43, 920-925.

Wondratschek, H. \& Jeitschko, W. (1976). Acta Cryst. A32, 664-666.

Zemann, J. (1981). Fortschr. Mineral. 59, 95-116. 


\section{supporting information}

Acta Cryst. (2017). E73, 975-979 [https://doi.org/10.1107/S2056989017008271]

\section{The phase transition of rubidium hydrogen carbonate, $\mathrm{RbHCO}_{3}$}

\section{Carla Larvor and Berthold Stöger}

\section{Computing details}

For both compounds, data collection: APEX3 (Bruker, 2016); cell refinement: SAINT-Plus (Bruker, 2016); data reduction: SAINT-Plus (Bruker, 2016). Program(s) used to solve structure: SHELXT (Sheldrick, 2015) for LT_RbHCO3. For both compounds, program(s) used to refine structure: Jana2006 (Petříček et al., 2014); molecular graphics: ATOMS (Dowty, 2006); software used to prepare material for publication: publCIF (Westrip, 2010).

(HT_RbHCO3)

Crystal data

$\mathrm{RbHCO}_{3}$

$M_{r}=146.5$

Monoclinic, $C 2 / m$

Hall symbol: $-\mathrm{C} 2 \mathrm{y}$

$a=14.807(3) \AA$

$b=5.8216(12) \AA$

$c=4.0217(9) \AA$

$\beta=104.321(5)^{\circ}$

$V=335.91(12) \AA^{3}$

$Z=4$

\section{Data collection}

Bruker KAPPA APEXII CCD diffractometer

Radiation source: X-ray tube $\omega$ - and $\varphi$-scans

Absorption correction: multi-scan

(SADABS; Bruker, 2016)

$T_{\min }=0.05, T_{\max }=0.27$

3067 measured reflections

\section{Refinement}

Refinement on $F^{2}$

$R\left[F^{2}>2 \sigma\left(F^{2}\right)\right]=0.029$

$w R\left(F^{2}\right)=0.066$

$S=1.26$

672 reflections

32 parameters

1 restraint

0 constraints
$F(000)=272$

$D_{\mathrm{x}}=2.897 \mathrm{Mg} \mathrm{m}^{-3}$

Mo $K \alpha$ radiation, $\lambda=0.71073 \AA$

Cell parameters from 1945 reflections

$\theta=2.8-32.6^{\circ}$

$\mu=14.54 \mathrm{~mm}^{-1}$

$T=270 \mathrm{~K}$

Rod, colourless

$0.43 \times 0.18 \times 0.09 \mathrm{~mm}$

672 independent reflections

544 reflections with $I>3 \sigma(I)$

$R_{\text {int }}=0.051$

$\theta_{\text {max }}=33.0^{\circ}, \theta_{\min }=2.8^{\circ}$

$h=-22 \rightarrow 20$

$k=-8 \rightarrow 8$

$l=-6 \rightarrow 6$

$\mathrm{H}$ atoms treated by a mixture of independent and constrained refinement

Weighting scheme based on measured s.u.'s $w=$ $1 /\left(\sigma^{2}(I)+0.0004 I^{2}\right)$

$(\Delta / \sigma)_{\max }=0.011$

$\Delta \rho_{\max }=0.86 \mathrm{e} \AA^{-3}$

$\Delta \rho_{\min }=-0.96$ e $\AA^{-3}$ 
Fractional atomic coordinates and isotropic or equivalent isotropic displacement parameters $\left(\AA^{2}\right)$

\begin{tabular}{llllll}
\hline & $x$ & $y$ & $z$ & $U_{\text {iso }} * / U_{\text {eq }}$ & Occ. $(<1)$ \\
\hline $\mathrm{Rb}$ & $0.66119(3)$ & 0 & $0.29537(9)$ & $0.02714(13)$ & \\
$\mathrm{O} 1$ & $0.6878(2)$ & 0.5 & $1.0996(8)$ & $0.0324(10)$ & \\
$\mathrm{O} 2$ & $0.57663(15)$ & $0.3079(3)$ & $0.7353(5)$ & $0.0304(7)$ & \\
$\mathrm{C}$ & $0.6159(3)$ & 0.5 & $0.8641(9)$ & $0.0210(10)$ & 0.5 \\
$\mathrm{H}$ & $0.522(2)$ & $0.328(12)$ & $0.608(16)$ & $0.04(2)^{*}$ & \\
\hline
\end{tabular}

Atomic displacement parameters $\left(\AA^{2}\right)$

\begin{tabular}{lllllll}
\hline & $U^{11}$ & $U^{22}$ & $U^{33}$ & $U^{12}$ & $U^{13}$ & $U^{23}$ \\
\hline $\mathrm{Rb}$ & $0.0363(3)$ & $0.02090(17)$ & $0.0221(2)$ & 0 & $0.00320(15)$ & 0 \\
$\mathrm{O} 1$ & $0.0244(16)$ & $0.0332(14)$ & $0.0343(16)$ & 0 & $-0.0030(13)$ & 0 \\
$\mathrm{O} 2$ & $0.0332(13)$ & $0.0173(8)$ & $0.0342(11)$ & $0.0018(7)$ & $-0.0040(9)$ & $-0.0016(7)$ \\
$\mathrm{C}$ & $0.0231(19)$ & $0.0186(14)$ & $0.0217(17)$ & 0 & $0.0062(14)$ & 0 \\
\hline
\end{tabular}

Geometric parameters $\left(A,{ }^{\circ}\right)$

\begin{tabular}{|c|c|c|c|}
\hline $\mathrm{Rb}-\mathrm{O} 1^{\mathrm{i}}$ & $2.869(3)$ & $\mathrm{Rb}-\mathrm{O} 2^{\mathrm{vi}}$ & $3.001(2)$ \\
\hline $\mathrm{Rb}-\mathrm{O} 1^{\mathrm{ii}}$ & $3.046(3)$ & $\mathrm{Rb}-\mathrm{C}^{\mathrm{iii}}$ & $3.370(2)$ \\
\hline $\mathrm{Rb}-\mathrm{O} 1^{\mathrm{iii}}$ & $3.0662(12)$ & $\mathrm{Rb}-\mathrm{C}^{\mathrm{iv}}$ & $3.370(2)$ \\
\hline $\mathrm{Rb}-\mathrm{O} 1^{\mathrm{iv}}$ & $3.0662(12)$ & $\mathrm{O} 1-\mathrm{C}$ & $1.237(4)$ \\
\hline $\mathrm{Rb}-\mathrm{O} 2^{\mathrm{iv}}$ & $2.908(2)$ & $\mathrm{O} 2-\mathrm{C}$ & $1.307(3)$ \\
\hline $\mathrm{Rb}-\mathrm{O} 2^{\mathrm{v}}$ & $2.908(2)$ & $\mathrm{O} 2-\mathrm{H}$ & $0.85(4)$ \\
\hline $\mathrm{Rb}-\mathrm{O} 2$ & $3.001(2)$ & & \\
\hline $\mathrm{O} 1^{\mathrm{i}}-\mathrm{Rb}-\mathrm{O} 2^{\mathrm{iv}}$ & $138.83(5)$ & $\mathrm{Rb}^{\mathrm{vii}}-\mathrm{O} 1-\mathrm{C}$ & $172.6(3)$ \\
\hline 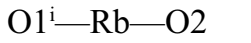 & $81.45(7)$ & $\mathrm{Rb}-\mathrm{O} 2-\mathrm{Rb}^{\text {viii }}$ & $85.75(5)$ \\
\hline $\mathrm{O} 1^{\mathrm{i}}-\mathrm{Rb}-\mathrm{O} 2^{\mathrm{v}}$ & $138.83(5)$ & $\mathrm{Rb}-\mathrm{O} 2-\mathrm{C}$ & $122.4(2)$ \\
\hline $\mathrm{O} 1^{\mathrm{i}}-\mathrm{Rb}-\mathrm{O} 2^{\mathrm{vi}}$ & $81.45(7)$ & $\mathrm{Rb}-\mathrm{O} 2-\mathrm{H}$ & $102(4)$ \\
\hline $\mathrm{O} 2^{\mathrm{iv}}-\mathrm{Rb}-\mathrm{O} 2$ & $85.75(6)$ & $\mathrm{Rb}^{\text {viii }}-\mathrm{O} 2-\mathrm{C}$ & 98.99 (16) \\
\hline $\mathrm{O} 2^{\mathrm{iv}}-\mathrm{Rb}-\mathrm{O} 2^{\mathrm{v}}$ & $76.10(5)$ & $\mathrm{Rb}^{\text {viii }-\mathrm{O} 2-\mathrm{H}}$ & $135(4)$ \\
\hline $\mathrm{O} 2^{\mathrm{iv}}-\mathrm{Rb}-\mathrm{O} 2^{\mathrm{vi}}$ & $131.47(6)$ & $\mathrm{C}-\mathrm{O} 2-\mathrm{H}$ & $113(5)$ \\
\hline $\mathrm{O} 2-\mathrm{Rb}-\mathrm{O} 2^{\mathrm{v}}$ & $131.47(6)$ & $\mathrm{O} 1-\mathrm{C}-\mathrm{O} 2$ & $121.17(15)$ \\
\hline $\mathrm{O} 2-\mathrm{Rb}-\mathrm{O} 2^{\mathrm{vi}}$ & $73.35(6)$ & $\mathrm{O} 1-\mathrm{C}-\mathrm{O} 2^{\mathrm{ix}}$ & $121.17(15)$ \\
\hline $\mathrm{O} 2^{\mathrm{v}}-\mathrm{Rb}-\mathrm{O} 2^{\mathrm{vi}}$ & $85.75(6)$ & $\mathrm{O} 2-\mathrm{C}-\mathrm{O} 2^{\mathrm{ix}}$ & $117.7(3)$ \\
\hline
\end{tabular}

Symmetry codes: (i) $-x+3 / 2, y-1 / 2,-z+2$; (ii) $-x+3 / 2, y-1 / 2,-z+1$; (iii) $x, y-1, z-1$; (iv) $x, y, z-1$; (v) $x,-y, z-1$; (vi) $x,-y, z$; (vii) $-x+3 / 2, y+1 / 2,-z+2$; (viii) $x, y, z+1$; (ix) $x,-y+1, z$.

Hydrogen-bond geometry $\left(\AA,{ }^{\circ}\right)$

\begin{tabular}{lllll}
\hline$D-\mathrm{H} \cdots A$ & $D-\mathrm{H}$ & $\mathrm{H} \cdots A$ & $D \cdots A$ & $D-\mathrm{H} \cdots A$ \\
\hline $\mathrm{O} 2-\mathrm{H} \cdots \mathrm{O} 2^{\mathrm{x}}$ & $0.85(4)$ & $1.75(4)$ & $2.571(3)$ & $162(6)$ \\
\hline
\end{tabular}

Symmetry code: $(\mathrm{x})-x+1, y,-z+1$. 


\section{(LT_RbHCO3)}

\section{Crystal data}

$\mathrm{RbHCO}_{3}$

$M_{r}=146.5$

Triclinic, $C \overline{1}$

Hall symbol: -C 1

$a=14.945(3) \AA$

$b=5.8212(9) \AA$

$c=3.9699(6) \AA$

$\alpha=89.343(4)^{\circ}$

$\beta=104.096(4)^{\circ}$

$\gamma=92.748(9)^{\circ}$

$V=334.59(9) \AA^{3}$

Data collection

Bruker KAPPA APEXII CCD

diffractometer

Radiation source: X-ray tube

$\omega$ - and $\varphi$-scans

Absorption correction: multi-scan

(TWINABS; Bruker, 2016)

$T_{\min }=0.05, T_{\max }=0.27$

8005 measured reflections

Refinement

Refinement on $F^{2}$

$R\left[F^{2}>2 \sigma\left(F^{2}\right)\right]=0.038$

$w R\left(F^{2}\right)=0.075$

$S=1.50$

1215 reflections

50 parameters

1 restraint

0 constraints
$Z=4$

$F(000)=272$

$D_{\mathrm{x}}=2.908 \mathrm{Mg} \mathrm{m}^{-3}$

Mo $K \alpha$ radiation, $\lambda=0.71073 \AA$

Cell parameters from 1945 reflections

$\theta=2.8-32.6^{\circ}$

$\mu=14.60 \mathrm{~mm}^{-1}$

$T=200 \mathrm{~K}$

Rod, colourless

$0.43 \times 0.18 \times 0.09 \mathrm{~mm}$

1215 independent reflections

1029 reflections with $I>3 \sigma(I)$

$R_{\text {int }}=0.059$

$\theta_{\text {max }}=32.7^{\circ}, \theta_{\min }=2.8^{\circ}$

$h=-6 \rightarrow 22$

$k=-8 \rightarrow 8$

$l=-6 \rightarrow 5$

$\mathrm{H}$ atoms treated by a mixture of independent and constrained refinement

Weighting scheme based on measured s.u.'s $w=$ $1 /\left(\sigma^{2}(I)+0.0004 I^{2}\right)$

$(\Delta / \sigma)_{\max }=0.018$

$\Delta \rho_{\max }=1.88$ e $\AA^{-3}$

$\Delta \rho_{\min }=-1.81$ e $\AA^{-3}$

Fractional atomic coordinates and isotropic or equivalent isotropic displacement parameters $\left(\hat{A}^{2}\right)$

\begin{tabular}{lllll}
\hline & $x$ & $y$ & $z$ & $U_{\mathrm{iso}} * / U_{\mathrm{eq}}$ \\
\hline $\mathrm{Rb}$ & $0.66221(2)$ & $-0.00995(4)$ & $0.29542(8)$ & $0.01812(10)$ \\
$\mathrm{O} 1$ & $0.68811(18)$ & $0.4885(4)$ & $1.0957(7)$ & $0.0232(8)$ \\
$\mathrm{O} 2$ & $0.57544(19)$ & $0.2938(4)$ & $0.7298(7)$ & $0.0218(8)$ \\
$\mathrm{O} 3$ & $0.57832(19)$ & $0.6790(4)$ & $0.7345(6)$ & $0.0219(8)$ \\
$\mathrm{C}$ & $0.6160(2)$ & $0.4961(5)$ & $0.8620(8)$ & $0.0153(9)$ \\
$\mathrm{H}$ & $0.529(2)$ & $0.326(7)$ & $0.570(10)$ & $0.037(13)^{*}$ \\
\hline
\end{tabular}

Atomic displacement parameters $\left(\AA^{2}\right)$

\begin{tabular}{lllllll}
\hline & $U^{11}$ & $U^{22}$ & $U^{33}$ & $U^{12}$ & $U^{13}$ & $U^{23}$ \\
\hline $\mathrm{Rb}$ & $0.02362(19)$ & $0.01426(16)$ & $0.01495(15)$ & $0.00035(9)$ & $0.00184(11)$ & $0.00014(9)$ \\
$\mathrm{O} 1$ & $0.0190(14)$ & $0.0226(11)$ & $0.0236(13)$ & $0.0006(8)$ & $-0.0032(10)$ & $0.0001(8)$ \\
$\mathrm{O} 2$ & $0.0227(14)$ & $0.0118(10)$ & $0.0266(13)$ & $0.0014(8)$ & $-0.0022(11)$ & $-0.0019(8)$ \\
$\mathrm{O} 3$ & $0.0256(14)$ & $0.0128(10)$ & $0.0223(12)$ & $0.0003(8)$ & $-0.0033(10)$ & $0.0007(7)$ \\
$\mathrm{C}$ & $0.0155(16)$ & $0.0151(13)$ & $0.0155(14)$ & $-0.0005(10)$ & $0.0047(12)$ & $-0.0003(9)$ \\
\hline
\end{tabular}


Geometric parameters $(\AA, \stackrel{o}{)}$

\begin{tabular}{|c|c|c|c|}
\hline $\mathrm{Rb}-\mathrm{O} 1^{\mathrm{i}}$ & $3.031(2)$ & $\mathrm{Rb}-\mathrm{O}^{\mathrm{v}}$ & $2.944(3)$ \\
\hline $\mathrm{Rb}-\mathrm{O} 1^{\mathrm{ii}}$ & $3.015(3)$ & $\mathrm{Rb}-\mathrm{C}^{\mathrm{iv}}$ & $3.324(3)$ \\
\hline $\mathrm{Rb}-\mathrm{O} 1^{\mathrm{iii}}$ & 2.865 & $\mathrm{Rb}-\mathrm{C}^{\mathrm{i}}$ & $3.408(3)$ \\
\hline $\mathrm{Rb}-\mathrm{O} 1^{\mathrm{iv}}$ & $3.101(2)$ & $\mathrm{O} 1-\mathrm{C}$ & $1.241(4)$ \\
\hline $\mathrm{Rb}-\mathrm{O} 2^{\mathrm{i}}$ & $2.926(2)$ & $\mathrm{O} 2-\mathrm{C}$ & $1.349(4)$ \\
\hline $\mathrm{Rb}-\mathrm{O} 2$ & $3.027(3)$ & $\mathrm{O} 2-\mathrm{H}$ & $0.85(3)$ \\
\hline $\mathrm{Rb}-\mathrm{O}^{\mathrm{iv}}$ & $2.885(2)$ & $\mathrm{O} 3-\mathrm{C}$ & $1.270(4)$ \\
\hline $\mathrm{O} 1^{\mathrm{i}}-\mathrm{Rb}-\mathrm{O} 1^{\mathrm{ii}}$ & $73.01(7)$ & $\mathrm{O}^{\mathrm{iv}}-\mathrm{Rb}-\mathrm{O}^{\mathrm{v}}$ & $85.85(7)$ \\
\hline $\mathrm{O} 1^{\mathrm{i}}-\mathrm{Rb}-\mathrm{O} 1^{\mathrm{iii}}$ & $94.75(6)$ & $\mathrm{Rb}^{\mathrm{vi}}-\mathrm{O} 1-\mathrm{Rb}^{\mathrm{ii}}$ & $106.99(8)$ \\
\hline $\mathrm{O} 1^{\mathrm{i}}-\mathrm{Rb}-\mathrm{O} 2^{\mathrm{i}}$ & $43.56(6)$ & $\mathrm{Rb}^{\mathrm{vi}}-\mathrm{O} 1-\mathrm{Rb}^{\mathrm{iii}}$ & $85.25(6)$ \\
\hline $\mathrm{O} 1^{\mathrm{i}}-\mathrm{Rb}-\mathrm{O} 2$ & $70.67(7)$ & $\mathrm{Rb}^{\mathrm{vi}}-\mathrm{O} 1-\mathrm{C}$ & $96.77(18)$ \\
\hline $\mathrm{O} 1^{\mathrm{i}}-\mathrm{Rb}-\mathrm{O} 3^{\mathrm{iv}}$ & $116.17(7)$ & $\mathrm{Rb}^{\mathrm{ii}}-\mathrm{O} 1-\mathrm{Rb}^{\mathrm{iii}}$ & $84.89(7)$ \\
\hline $\mathrm{O} 1^{\mathrm{i}}-\mathrm{Rb}-\mathrm{O}^{\mathrm{v}}$ & $144.31(8)$ & $\mathrm{Rb}^{\mathrm{ii}}-\mathrm{O} 1-\mathrm{C}$ & $103.4(2)$ \\
\hline $\mathrm{O} 1^{\mathrm{ii}-\mathrm{Rb}}-\mathrm{O} 1^{\mathrm{iii}}$ & $84.89(8)$ & $\mathrm{Rb}^{\mathrm{iii}}-\mathrm{O} 1-\mathrm{C}$ & $170.4(3)$ \\
\hline $\mathrm{O} 1^{\mathrm{ii}}-\mathrm{Rb}-\mathrm{O} 2^{\mathrm{i}}$ & $81.38(7)$ & $\mathrm{Rb}-\mathrm{O} 2-\mathrm{Rb}^{\mathrm{vi}}$ & $83.64(6)$ \\
\hline $\mathrm{O} 1 \mathrm{ii}-\mathrm{Rb}-\mathrm{O} 2$ & $140.08(6)$ & $\mathrm{Rb}-\mathrm{O} 2-\mathrm{C}$ & $122.1(2)$ \\
\hline $\mathrm{O} 1^{\mathrm{ii}-}-\mathrm{Rb}-\mathrm{O} 3^{\mathrm{iv}}$ & $80.76(7)$ & $\mathrm{Rb}-\mathrm{O} 2-\mathrm{H}$ & $97(3)$ \\
\hline $\mathrm{O} 1^{\mathrm{ii}-}-\mathrm{Rb}-\mathrm{O}^{\mathrm{v}}$ & $141.28(7)$ & $\mathrm{Rb}^{\mathrm{vi}}-\mathrm{O} 2-\mathrm{C}$ & $98.99(17)$ \\
\hline 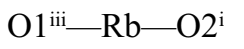 & $138.29(6)$ & $\mathrm{Rb}^{\mathrm{vi}}-\mathrm{O} 2-\mathrm{H}$ & $149(3)$ \\
\hline $\mathrm{O} 1{ }^{\mathrm{iii}}-\mathrm{Rb}-\mathrm{O} 2$ & $82.17(7)$ & $\mathrm{C}-\mathrm{O} 2-\mathrm{H}$ & $107(3)$ \\
\hline 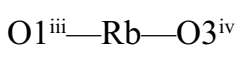 & $139.80(7)$ & $\mathrm{Rb}^{\mathrm{vii}}-\mathrm{O} 3-\mathrm{Rb}^{\mathrm{viii}}$ & $85.85(6)$ \\
\hline $\mathrm{O} 1^{\mathrm{iii}-\mathrm{Rb}-\mathrm{O}^{\mathrm{v}}}$ & $82.33(7)$ & $\mathrm{Rb}^{\mathrm{vii}}-\mathrm{O} 3-\mathrm{C}$ & $121.9(2)$ \\
\hline $\mathrm{O} 2 \mathrm{i}-\mathrm{Rb}-\mathrm{O} 2$ & $83.64(7)$ & $\mathrm{Rb}^{\text {viii }}-\mathrm{O} 3-\mathrm{C}$ & $98.73(18)$ \\
\hline $\mathrm{O} 2^{\mathrm{i}}-\mathrm{Rb}-\mathrm{O} 3^{\mathrm{iv}}$ & $76.08(6)$ & $\mathrm{O} 1-\mathrm{C}-\mathrm{O} 2$ & $117.2(3)$ \\
\hline $\mathrm{O} 2^{\mathrm{i}}-\mathrm{Rb}-\mathrm{O}^{\mathrm{v}}$ & $130.12(8)$ & $\mathrm{O} 1-\mathrm{C}-\mathrm{O} 3$ & $125.2(3)$ \\
\hline $\mathrm{O} 2-\mathrm{Rb}-\mathrm{O} 3^{\mathrm{iv}}$ & $130.57(7)$ & $\mathrm{O} 2-\mathrm{C}-\mathrm{O} 3$ & $117.6(3)$ \\
\hline $\mathrm{O} 2-\mathrm{Rb}-\mathrm{O}^{\mathrm{v}}$ & $73.70(7)$ & & \\
\hline
\end{tabular}

Symmetry codes: (i) $x, y, z-1$; (ii) $-x+3 / 2,-y+1 / 2,-z+1$; (iii) $-x+3 / 2,-y+1 / 2,-z+2$; (iv) $x, y-1, z-1$; (v) $x, y-1, z$; (vi) $x, y, z+1$; (vii) $x, y+1, z$; (viii) $x$, $y+1, z+1$.

Hydrogen-bond geometry $\left(\AA,{ }^{\circ}\right)$

\begin{tabular}{lllll}
\hline$D-\mathrm{H}^{*} \cdots A$ & $D-\mathrm{H}$ & $\mathrm{H} \cdots A$ & $D \cdots A$ & $D-\mathrm{H} \cdots A$ \\
\hline $\mathrm{O} 2-\mathrm{H}^{\cdots} \mathrm{O}^{\text {ix }}$ & $0.85(3)$ & $1.75(3)$ & $2.582(3)$ & $165(4)$
\end{tabular}

Symmetry code: (ix) $-x+1,-y+1,-z+1$. 